\title{
RESEARCH
}

\section{A PILOT STUDY OF CLINICAL PHARMACIST- LED MEDICATION REVIEW IN OLDER ADULTS ON POLYPHARMACY AND RECEIVING HOME HEALTH CARE SERVICES}

Turkish Journal of Geriatrics

DOI: 10.31086/tjgeri.2020.190

2020; 23(4): 515-523

\section{- Semra MEMiş ${ }^{1}$ (D) \\ - Mesut SANCAR ${ }^{1}$ (D) \\ - Onursal VARLIKLI \\ - Betül AKÇAY² (D) \\ - Halide VAROL ${ }^{2}$ (D) \\ - Sümeyra Lubeyne SÖYLEMEZ1 ${ }^{1}$ \\ - Mahmut Sabri MEDişOǦLU2 \\ - Betul OKUYAN ${ }^{1}$ (D)}

CORRESPONDANCE

\section{Betul OKUYAN}

Marmara University, Faculty of Pharmacy,

Clinical Pharmacy Department, Istanbul, Turkey

Phone: +905333300353

e-mail: betulokuyan@yahoo.com

Received: Sep 22, 2020

Accepted: Nov 17, 2020

${ }^{1}$ Marmara University, Faculty of Pharmacy,

Clinical Pharmacy Department, Istanbul,

Turkey

${ }^{2}$ Republic of Turkey Ministry of Health,

Kocaeli Provincial Health Directorate, Health

Services at Home, Kocaeli, Turkey

\section{Abstract}

Introduction: This study aimed to evaluate the frequency and types of medication-related problems in older adults receiving home health care services that were identified through clinical pharmacist-led medication review.

Materials and Methods: This pilot study was conducted in patients $\geq 65$ years of age who were on polypharmacy and receiving home health care services from May $15^{\text {th }}, 2019$ through October $30^{\text {th }}, 2019$ in Turkey. A multidisciplinary home care team, including physicians, nurses and clinical pharmacist, performed the home visits. Scores on the drug burden index, medication regimen complexity index, and medication appropriateness index, present of potentially inappropriate medications, and the medication-related problems were assessed.

Results: Among 100 older adults ( 74 females) with a mean age of $78.5 \pm 7.9$ years, the median number of medications used was 7 (interquartile range: 5-9); the median scores of the drug burden index, medication regimen complexity, and medication appropriateness index were 0.5 (interquartile range: 0-0.8), 21 (interquartile range: 17-31), and 13 (interquartile range: 6-16.9), respectively. The problems identified were those related to 'drug selection' (66\%), 'education and information' $(58 \%)$ and 'monitoring' (33\%). The health care team accepted $84.2 \%$ of the recommendations made by the clinical pharmacists.

Conclusions: The results suggested that clinical pharmacist-led cognitive services in a home health care services team could reduce medication-related problems in older adults on polypharmacy.

Keywords: Pharmacists; Home Care Services; Polypharmacy 


\section{INTRODUCTION}

Older adults receiving home healthcare services with polypharmacy are susceptible to medicationrelated problem (1). A 'Medication Management Model' is defined as structured interprofessional services that involves clinical pharmacists and home health nurses (2). As a part of this interprofessional model developed for home health providers, home visits were conducted by pharmacists for home care patients on polypharmacy ( $\geq 9$ medications) and a total of 2,482 medication-related problems were determined (3). The advantages of these pharmacy services conducted in the home setting have been reported as providing a comfortable place for discussing many issues, enabling the development of an accurate medication list and allowing functional medication administration for participants (3).

The home medicines review (HMR) is a community-based service that involves general practitioners and pharmacists in order to prevent, determine, and resolve medication-related problems in Australia (4). The drug burden index (DBI) (5) and medication appropriateness index (MAI) (6) are evidence-based tools that are used to demonstrate potential contribution of pharmacist-led HMR (4). Home health care services have recently been integrated into the health system in Turkey; however, pharmacists are not involved in the home care services team that includes physicians and nurses. A novel project was initiated in 2019 by the Kocaeli Provincial Health Directorate in cooperation with the Clinical Pharmacy Department of Marmara University Faculty of Pharmacy. This project aimed to provide education and training for pharmacists on cognitive services in home health care services and to develop clinical pharmacy services that could be integrated into the health care services in the home setting. As a part of this project, the present pilot study aimed to evaluate the potential impact of providing medication review in older adults on polypharmacy and receiving home health care services. For this purpose, the frequency and types of medication-related prob- lems were determined through the clinical pharmacist-led medication review in older adults who were on polypharmacy and receiving home health care services, and acceptance rate of the pharmacists' recommendations by the health care team (the physicians and nurses) were assessed.

\section{MATERIALS AND METHODS}

\section{Ethics Approval}

The present study was approved by the Clinical Trial Ethics Committee of University of Health Sciences Kocaeli Derince Training and Research Hospital of (approval number: 2019-40, date: May $9^{\text {th }}$ 2019). The informed consents of the patients and/ or their caregivers was obtained before the study.

\section{Setting and Study Design}

This descriptive cross-sectional pilot study was conducted from May 15th 2019 through October $30^{\text {th }}, 2019$. Patients aged $\geq 65$ years who were on polypharmacy (defined as concurrently used 4 or more medications based on previous study) (7) and receiving health care services in the home setting in the Kocaeli province of Turkey were eligible for participation.

\section{Clinical Pharmacist-Led Medication Review}

A multidisciplinary home care team including physicians and nurses performed weekly or daily visits to evaluate the patients. A clinical pharmacist joined the health care team within the time frame of the present study. During the home visits, the pharmacists interviewed with the older adults and/ or their caregivers about their medications.

\section{Data Collection}

The data of the older adults regarding age, sex, number of years of education, history of falls, comorbidities, and hospital admissions during the previous six months were obtained from the med- 
ical records. All medications, including medications with or without prescription and dietary supplements, were recorded for each patient and biochemical test results were also obtained from the medical records of each patient.

DBI scores were calculated for all patients. The $\mathrm{DBI}$ is an evidence-based tool that assesses the total exposure of older adults to anticholinergic and sedative medications (5). A previously published list was used as a reference to determine the minimum effective dose of medications (8).

The medication complexity of each patient was quantified using the Turkish version of the Medication Regimen Complexity Index (MRCl) (9). The $\mathrm{MRCl}$ is a 65-item valid tool that evaluates the medication complexity of patients according to the dosage forms, dosage frequency, and administration instructions of medications. Higher scores indicate more complex medication regimens (9).

\section{Medication Related Problems}

The appropriateness of all medications used by the patients was assessed with the MAI. This index contains 10 criteria, each of which is scored as appropriate, neutral, inappropriate, or unknown, and it yields a maximum potential score of 18 . Lower scores indicate the appropriateness, whereas higher scores indicate inappropriateness of medication (6). The Potentially inappropriate medications (PIMs) used by the patients were determined with the 2019 American Geriatrics Society (AGS) Beers Criteria ${ }^{\circledR}(10)$ and TIME-to-STOP criteria (11).

The medication-related problems were determined by the clinical pharmacist-led medication review and listed by using the validated DOCUMENT classification system (12). The health care providers' (the physicians and the nurses) acceptance rate of clinical pharmacist's recommendations about the medication-related problems was recorded without evaluating the outcome of implementation these recommendations.

\section{Statistical Analysis}

The data analysis was performed using the Statistical Package for the Social Sciences for Windows (version 11; SPSS Inc., Chicago, IL, USA). The normality of data distribution was tested by using the Kolmogorov-Smirnov test. Data were expressed as median (interquartile range [IQR]) and mean and standard deviation (SD) for continuous variables and as frequency and percentage for categorical variables.

\section{RESULTS}

A total of 124 older adults who were receiving home health care services were visited during the study period, of which 19 had insufficient medication and clinical data, and five were not willing to participate in the study. Accordingly, the study was conducted in 100 older adults who were on polypharmacy and receiving home health care services. The mean age was $78.5 \pm 7.9$ years; the majority of the patients were female $(74 \%)$ and had less than eight years of education (97\%). Nearly half of the patients (49\%) had a hospital admission within the last six months, and 28 patients had a history of fall. The median total number of medications was 7 (IQR: 5-9). The median DBI score was calculated as 0.5 (IQR: 0-0.8). According to the DBI scores, a high exposure to anticholinergic and sedative medicines was determined in 22 older adults. The median total $\mathrm{MRCl}$ score was 21 (IQR: 17-31), and the median total MAI score was calculated as 13 (IQR: 6.0-16.9). The demographic and medical data of them included in the study are presented in Table 1.

Among the study patients, $40 \%$ were using PIMs according to the TIME-to-STOP criteria, and 7.0\% of the all medications used ( $n=738$ ) were PIMs. The MAI scores and the number of PIMs are presented in Table 2. At least one of the 2019 Beers Criteria $₫$ was determined in 53 of the patients receiving health care services in the home setting. The number of PIMs for the older adults receiving health care services in the home setting is summarized in Table 3. 
Table 1. Demographic and medical data of older adults receiving home care services (number of patients=100)

\begin{tabular}{|c|c|}
\hline & $n$ \\
\hline Age (years) Mean (SD) & $78.5(7.9)$ \\
\hline \multicolumn{2}{|l|}{ Gender (\%) } \\
\hline Male & 26 \\
\hline Female & 74 \\
\hline \multicolumn{2}{|l|}{ Education (years) (\%) } \\
\hline$<8$ & 97 \\
\hline$\geq 8$ & 3 \\
\hline \multicolumn{2}{|l|}{ Hospital admission during last 6 months (\%) } \\
\hline Yes & 49 \\
\hline No & 51 \\
\hline \multicolumn{2}{|l|}{ History of Falls (\%) } \\
\hline Yes & 28 \\
\hline No & 72 \\
\hline Total number of medication Median (IQR) & $7(5-9)$ \\
\hline DBI score Median (IQR) & $0.5(0-0.8)$ \\
\hline \multicolumn{2}{|l|}{ DBI score } \\
\hline 0 & 35 \\
\hline$<1$ & 43 \\
\hline$\geq 1$ & 22 \\
\hline $\mathrm{MRCl}$ score Median (IQR) & $21(17-31)$ \\
\hline MAI score Median (IQR) & $13(6.0-16.9)$ \\
\hline
\end{tabular}

SD: standard deviation; IQR: interquartile range DBI: drug burden index; MRCl: medication regimen complexity index; MAI: Medication Appropriateness Index

Table 2. Medication appropriateness index score and the number of PIMs (total number of medications=738)

\begin{tabular}{|c|c|}
\hline & A total number of medications (\%) \\
\hline \multicolumn{2}{|l|}{$\mathrm{MAl}$} \\
\hline 0 & $259(35.1 \%)$ \\
\hline $1-2$ & $298(40.4 \%)$ \\
\hline $3-4$ & $112(15.1 \%)$ \\
\hline$\geq 5$ & $59(9.5 \%)$ \\
\hline \multicolumn{2}{|c|}{ PIMs according to TIME-to STOP Criteria } \\
\hline No & $686(93 \%)$ \\
\hline Yes & $52(7 \%)$ \\
\hline \multicolumn{2}{|c|}{ At least one PIM according to 2019 AGS Beers ${ }^{\circledR}$ Criteria } \\
\hline Yes & $90(12.2 \%)$ \\
\hline No & $648(87.8 \%)$ \\
\hline
\end{tabular}

MAI: Medication Appropriateness Index; PIM: potentially inappropriate medication; TIME to STOP: criteria for inappropriate medication use in Turkish older adults; AGS: American Geriatrics Society

For the older adults who were on polypharmacy, 329 medication-related problems were determined by the clinical pharmacist-led medication review, and $96 \%$ of the patients had at least one medication-related problem. Those problems were 'problems related to drug selection' (66\%), 'problems related to education and information' (58\%) and 'problems related to monitoring' (33\%). Of the 329 recommendations of the pharmacists, $84.2 \%$ were accepted by the home health care team. The medication-related problems identified according to the DOCUMENT classification system for the patients 
Table 3. PIMs in older adults receiving health care services at home setting (the number of patients=100)

\begin{tabular}{|c|c|}
\hline PIMs according to TIME-to STOP Criteria & $\mathrm{n}$ \\
\hline 0 & 60 \\
\hline 1 & 30 \\
\hline 2 & 7 \\
\hline 3 & 3 \\
\hline \multicolumn{2}{|c|}{2019 AGS Beers Criteria ${ }^{\circledR}$ - PIM in Older Adults Due to Drug-Disease or Drug-Syndrome Interactions } \\
\hline 0 & 76 \\
\hline 1 & 24 \\
\hline \multicolumn{2}{|c|}{2019 AGS Beers Criteria® - PIM in Older Adult } \\
\hline 0 & 54 \\
\hline 1 & 34 \\
\hline 2 & 12 \\
\hline \multicolumn{2}{|c|}{2019 AGS Beers Criteria ${ }^{\circledR}$ - Potentially Clinically Important Drug-Drug Interactions } \\
\hline 0 & 88 \\
\hline 1 & 12 \\
\hline \multicolumn{2}{|c|}{$\begin{array}{l}2019 \text { AGS Beers Criteria }{ }^{\circledR} \text { - Medications That Should Be Avoided or Have Their Dosage Reduced with } \\
\text { Kidney Function of Older Patient }\end{array}$} \\
\hline 0 & 98 \\
\hline 1 & 2 \\
\hline
\end{tabular}

PIM: potentially inappropriate medication; AGS: American Geriatrics Society; TIME to STOP: criteria for inappropriate medication use in Turkish older adults

are summarized in Table 4. The most commonly observed medication-related problems in older patients are summarized in Table 5.

\section{DISCUSSION}

The results of the present study, which investigated medication-related problems in older adults who were on polypharmacy and receiving home health care services, demonstrated that the majority of the patients (96\%) had at least one medication-related problem determined by the clinical pharmacist. The problems identified were those related to 'drug selection' (66\%), 'education and information' (58\%) and 'monitoring' (33\%). The health care team accepted $84.2 \%$ of the recommendations made by the clinical pharmacists.

The total number of medications was determined to be slightly lower than those reported in previous studies conducted in the home setting $(13,14)$. Among our patients, the rate of those highly exposed to medications identified by the DBI was $22 \%$. Similar to the results of the present study, the rate of exposure to medications identified by the DBI was shown to be nearly one fifth of them (15). In contrast, the rate of exposure to anticholinergic and/or sedative medications identified by the DBI in older patients has been reported to be higher in the community setting (7).

The median $\mathrm{MRCl}$ score was determined as 21 (IQR, 17-31) in the patients of this study; this finding was in parallel with the results reported in previous studies $(16,17)$. However, the median total MAI score 13 [IQR, 6.0-16.9]) found in the present study was higher than that reported in previous studies $(13,18)$.

In a retrospective study on community-dwelling older individuals ( $\geq 65$ years; $n=270$ ) in Australia, 
in which the effects of HMRs performed by pharmacists on prescribing appropriateness (13), were evaluated, the most common medication-related problems were reported as medications with no indication (22.0\%), potential drug-drug interactions (14.3\%) and problems related to dosage (13.0\%). Additionally, the acceptance rate of the pharmacists' suggestions by the general practitioners was reported as $45.5 \%$ (13), a finding which was lower than the finding of the present study (84.2\%). In contrast, similar to the rate found in the present study, the rate of receiving at least one PIM was reported to be $59 \%$ in patients with dementia living at home (19) and $40.4 \%$ in older home care patients in Japan (20). In a study conducted in Switzerland, 2.2\% of all prescribed medications were identified as PIMs by clinical pharmacists in the patients transferred from hospital to home care (21). In Qatar, the ratio of patients receiving at least one PIM was 38.2\% among older home care patients (22). In a study from Europe, overall, $19.8 \%$ of patients were reported to receive at least one PIM (23); the rate of those receiving at least one PIM was reported as $41.1 \%$ in the Czech Republic (23), and this rate was similar to the finding of the present study.

In a study performed to investigate the recommendations made by geriatric clinical pharmacists through medication reviews for patients with dementia living at home, the health care providers accepted $44 \%$ of the recommendations made by the geriatric clinical pharmacists (19); these recommendations included those related to the cessa-

Table 4. Medication-related problems identified according to DOCUMENT in the study population (the number of patients=100)

\begin{tabular}{|c|c|c}
\hline The type of medication related problems & The number of patients & The number of recommendations $n(\%)$ \\
\hline Drug selection & 66 & $111(33.7)$ \\
\hline Education or information & 58 & $77(23.4)$ \\
\hline Monitoring & 33 & $40(12.1)$ \\
\hline Toxicity or adverse reaction & 29 & $38(11.5)$ \\
\hline Over or underdose & 24 & $29(8.8)$ \\
\hline Compliance & 21 & $27(8.2)$ \\
\hline Undertreated & 7 & $7(2.1)$ \\
\hline
\end{tabular}

Table 5. The most commonly determined medication related problems in the older adults receiving health care services at home setting (the number of patients=100)

\begin{tabular}{|l|c|}
\hline The most commonly determined medication related problems & $\mathrm{n}$ \\
\hline $\begin{array}{l}\text { Problems related medication administration such as lack of information about how and } \\
\text { when to take medications }\end{array}$ & 72 \\
\hline $\begin{array}{l}\text { Anticholinergic and sedative utilization that are resulted in ataxia, impaired psychomotor } \\
\text { function, additional falls }\end{array}$ & 50 \\
\hline Utilization of PPI more than 8 weeks & 35 \\
\hline Combination of three or more CNS active agents concomitantly & 11 \\
\hline Dose adjustment is required & 13 \\
\hline
\end{tabular}

PPI: proton pump inhibitors, CNS: central nervous system 
tion of a drug, dose adjustment, and switching to a potentially safer alternative (19). In another study conducted among older adults receiving home care services and using at least five medications in the Netherlands, a total of 1,565 medication-related problems were determined (14). In contrast to the results of the present study, the most common medication-related problems were reported to be associated with medication selection (28\%), untreated indication (26\%), and monitoring (21\%) (14). In a study from Canada, medication-related problems were detected in patients receiving home care services through pharmacist-led medication review (24). Moreover, the acceptance rate of the pharmacists' recommendations by the physicians was reported to be $69.9 \%$, which was a lower rate than that found in the present study $(84.2 \%)$, and the most common medication-related problems were identified as medication adherence problems (37.6\%), unnecessary medication use (16.6\%), need for an additional treatment (12.9\%), and problems related to dosage (12.9\%) (24). A randomized control trial in Jordan evaluated the effects of the medication management review service via home visits in the intervention group as compared with a control group through pharmacist-led medication review (25). The most common medication-related problems according to clinical pharmacists were reported to be associated with education (27.2\%), inappropriate adherence (16.5\%), and issues with monitoring (15.8\%). At the end of the study, $85.0 \%$ of the medication-related problems identified by the clinical pharmacist in the intervention group were corrected (25).

The medications used by participants were evaluated in detail using the $\mathrm{MRCl}, \mathrm{MAl}, \mathrm{DBI}$, and the PIMs and medication-related problems were also assessed; these could be considered as strengths of the study. Nevertheless, the present study has some limitations. First, the small sample size from a specific region could be considered a limitation. However, the potential impact of the pharmacist-led medication review on clinical and patient-related outcomes was not evaluated; this could be considered another limitation, which is attributed to the cross-sectional design of the study. This study presented a low evidence with current study design for potential impact of the pharmacists in the home care team. This study was determined the medication related problems and their frequency, and the acceptance rate of the pharmacist's recommendations. The future studies would be conducted to evaluate impact of these recommendations' implementation on the older patients' outcomes at home care setting.

This pilot study elucidates the potential impact of integrating the pharmacist into a health care team to determine and solve medication-related problems. These findings may be helpful in training the pharmacist for cognitive services such as medication review for older patients receiving home health care services. The findings of the present study could also encourage the development of programs and/or care models involving pharmacists for home health care services in Turkey and other countries where the development and implementation of clinical pharmacy services are ongoing.

\section{Acknowledgments}

None

\section{Disclosure statement}

We have no conflict of interest to declare. 


\section{REFERENCES}

1. Meredith S, Feldman PH, Frey D, et al. Possible medication errors in home healthcare patients. J Am Geriatr Soc 2001;49(6):719-24. (PMID: 11454109).

2. Meredith S, Feldman P, Frey D, et al. Improving medication use in newly admitted home healthcare patients: A randomized controlled trial. J Am Geriatr Soc 2002;50(9):1484-91. (PMID: 12383144).

3. Reidt S, Morgan J, Larson T, Blade MA. The role of a pharmacist on the home care team: a collaborative model between a college of pharmacy and a visiting nurse agency. Home Healthc Nurse 2013;31(2):80-7; quiz 8-9. (PMID: 23314201).

4. Chen TF. Pharmacist-Led Home Medicines Review and Residential Medication Management Review: The Australian Model. Drugs Aging 2016;33(3):199204. (PMID: 26961696).

5. Hilmer SN, Mager DE, Simonsick EM, et al. A drug burden index to define the functional burden of medications in older people. Arch Intern Med 2007;167(8):781-7. (PMID: 17452540).

6. Hanlon JT, Schmader KE, Samsa GP, et al. A method for assessing drug therapy appropriateness. J Clin Epidemiol 1992;45(10):1045-51. (PMID: 1474400).

7. Rankin A, Cadogan CA, Patterson SM, et al. Interventions to improve the appropriate use of polypharmacy for older people. Cochrane Database Syst Rev. 2018;9(9):CD008165. (PMID: 30175841).

8. Byrne CJ, Walsh C, Cahir C, Ryan C, Williams DJ, Bennett K. Anticholinergic and sedative drug burden in community-dwelling older people: a national database study. BMJ Open 2018;8(7):e022500. (PMID: 29982221).

9. Okuyan B, Babi B, Sancar M, et al. Validation of the Turkish version of medication regimen complexity index among elderly patients. J Eval Clin Pract 2016;22(5):732-6. (PMID: 26987572).

10. By the 2019 American Geriatrics Society Beers Criteria $($ Update Expert Panel. American Geriatrics Society 2019 Updated AGS Beers Criteria $®$ for Potentially Inappropriate Medication Use in Older Adults. J Am Geriatr Soc 2019;67(4):674-94. (PMID: 30693946).

11. Bahat $G$, Ilhan $B$, Erdogan $T$, et al. Turkish inappropriate medication use in the elderly (TIME) criteria to improve prescribing in older adults: TIME-to-STOP/ TIME-to-START. Eur Geriatr Med 2020;11(3):491-98. (PMID: 32297261).
12. Williams M, Peterson G, Tenni P, BindoffI, Stafford A. DOCUMENT: a system for classifying drug-related problems in community pharmacy. Int J Clin Pharm 2012;34(1):43-52. (PMID: 22101425).

13. Castelino RL, Bajorek BV, Chen TF. Retrospective evaluation of home medicines review by pharmacists in older Australian patients using the medication appropriateness index. Ann Pharmacother 2010;44(12):1922-9. (PMID: 21119095).

14. Kwint HF, Faber A, Gussekloo J, Bouvy ML. The contribution of patient interviews to the identification of drug-related problems in home medication review. J Clin Pharm Ther 2012;37(6):674-80. (PMID: 22861493).

15. Zhang $X L$, Zhou S, Li $X R$, et al. Anticholinergic and sedative medications exposure in older patients: a cross-sectional study. Int J Clin Pharm 2019;41(5):1152-8. (PMID: 31392583).

16. Elliott RA, O'Callaghan C, Paul E, George J. Impact of an intervention to reduce medication regimen complexity for older hospital inpatients. Int J Clin Pharm 2013;35(2):217-24. (PMID: 23212732).

17. Saez de la Fuente J, Such Diaz A, Cañamares-Orbis I, et al. Cross-cultural Adaptation and Validation of the Medication Regimen Complexity Index Adapted to Spanish. Ann Pharmacother 2016;50(11):918-25. (PMID: 27371950).

18. Spinewine A, Swine C, Dhillon S, et al. Effect of a collaborative approach on the quality of prescribing for geriatric inpatients: a randomized, controlled trial. J Am Geriatr Soc 2007;55(5):658-65. (PMID: 17493184).

19. Melville BL, Bailey J, Moss J, et al. Description of Pharmacist Recommendations in the Caring for Older Adults and Caregivers at Home (COACH) Program. Sr Care Pharm 2020;35(1):38-46. (PMID: 31883544).

20. Hamano J, Tokuda Y. Inappropriate prescribing among elderly home care patients in Japan: prevalence and risk factors. J Prim Care Community Health 2014;5(2):90-6. (PMID: 24399442).

21. Meyer-Massetti C, Hofstetter $V$, Hedinger-Grogg B, Meier CR, Guglielmo BJ. Medication-related problems during transfer from hospital to home care: baseline data from Switzerland. Int J Clin Pharm 2018;40(6):1614-20. (PMID: 30291577). 
22. Alhmoud E, Khalifa S, Bahi AA. Prevalence and predictors of potentially inappropriate medications among home care elderly patients in Qatar. Int J Clin Pharm 2015;37(5):815-21. (PMID: 25986290).

23. Fialová D, Topinková E, Gambassi G, et al. Potentially inappropriate medication use among elderly home care patients in Europe. JAMA 2005;293(11):1348-58. (PMID: 15769968).
24. Walus AN, Woloschuk DMM. Impact of Pharmacists in a Community-Based Home Care Service: A Pilot Program. Can J Hosp Pharm 2017;70(6):435-42. (PMID: 29299003).

25. Basheti IA, Al-Qudah RA, Obeidat NM, Bulatova NR. Home medication management review in outpatients with chronic diseases in Jordan: a randomized control trial. Int J Clin Pharm 2016;38(2):404-13. (PMID: 26960406). 